\title{
Contribuições de Paulo Freire para a formação de educadores: fundamentos e práticas de um paradigma contra-hegemônico
}

\section{Paulo Freire's contributions to teacher education: foundations and practices of a counter-hegemonic paradigm}

\author{
Ana Maria Saul ${ }^{1}$ \\ Alexandre Saul ${ }^{1}$
}

\section{RESUMO}

O artigo tem o objetivo de apresentar a proposta de formação permanente de Paulo Freire como um paradigma contra-hegemônico, capaz de reagir criticamente aos modelos dominantes de formação. $\mathrm{O}$ texto expõe um panorama das críticas que vêm sendo feitas às políticas e práticas de formação de educadores e às racionalidades subjacentes às propostas que disputam projetos nesse campo de estudos e pesquisas. Na sequência, o paradigma de formação permanente de Paulo Freire, posto em ação na Secretaria de Educação do município de São Paulo (1989-1992), é discutido como uma possibilidade para construir, coletivamente, novas formas de agir e pensar na formação docente, em uma perspectiva crítico-transformadora. Por fim, são apontados resultados da pesquisa "Paulo Freire na atualidade: legado e reinvenção", que busca evidenciar a materialidade e a reinvenção do pensamento de Freire, em diferentes contextos educativos da realidade brasileira, no eixo da formação docente. A pesquisa tem sua origem na Cátedra Paulo Freire da Pontifícia Universidade Católica de São Paulo (PUC-SP) e vem se desenvolvendo em uma rede que congrega 28 pesquisadores vinculados a 14 Programas de Pós-Graduação em Educação, em 10 estados.

Palavras-chave: Paulo Freire; formação de educadores; formação permanente; Cátedra Paulo Freire da PUC-SP.

DOI: $10.1590 / 0104-4060.46865$

1 Pontifícia Universidade Católica de São Paulo. Programa de Estudos Pós-Graduados em Educação. São Paulo, São Paulo, Brasil. Rua Ministro Godói, n ${ }^{\circ} 969-4^{\circ}$ andar, sala 4E-15. CEP: 05.015-000.E-mail: anasaul@uol.com.bre asaul@hotmail.com 


\begin{abstract}
This article aims to present Paulo Freire's proposal of permanent teacher education, as a counter-hegemonic paradigm, able to react critically to the dominant models of teacher education. The text presents an overview of the criticisms that have been made to policies and practices of teachers' education and underlying rationalities on the proposals that compete for projects in this field of studies and research. Following, Freire's paradigm of permanent teacher education, put into action in the Education Secretariat of the municipality of São Paulo (1989-1992), is discussed as a possibility to build, collectively, new ways of acting and thinking in teacher education, on a critical and transforming perspective. At the end, results of the research "Paulo Freire today: legacy and reinvention" are appointed, which seek to demonstrate the materiality and reinvention of Freire's thought in different educational contexts from the Brazilian reality, in the axis of teacher education. This research has its origin in the Paulo Freire's Cathedra from Pontifícia Universidade Católica de São Paulo (PUC-SP), that has been developed in a network design, that brings together 28 researchers from 14 Graduate Programs in Education, in 10 Brazilian states.
\end{abstract}

Keywords: Paulo Freire; teacher education; permanent teacher education; Paulo Freire's Cathedra of PUC-SP.

\title{
Primeiras palavras
}

A formação de educadores não é um tema novo, como é possível constatar nas obras de Nóvoa (1995), Marcelo (2013), Imbernón (2010), Celani (1988) e Candau (2007). A partir dos anos 1970 do século 20, de forma sistemática, tem sido objeto de preocupação da crítica e da pesquisa de educadores, responsáveis pelas políticas públicas de educação e reformadores empresariais que, com diferentes interesses e perspectivas, concordam sobre sua centralidade nas propostas que envolvem mudanças nos sistemas educativos.

Estrela (2006) aponta que o destaque e a visibilidade que a formação de professores vem ganhando possuem várias faces. A face mais visível corresponde aos esforços legislativos, às horas e horas de formação realizadas - que buscam responder aos desafios colocados aos sistemas de educação e às dificuldades da prática pedagógica cotidiana - e à produção de pesquisas e publicações especializadas sobre o fenômeno formativo. Há uma face menos visível, talvez a mais nobre, que diz respeito aos efeitos da formação sobre os educadores e a comunidade escolar, acrescida da luta dos educadores por melhores condições 
de trabalho, crescimento pessoal e valorização profissional. Finalmente, há também uma face escondida e menos nobre, a "face do negócio", que se reporta aos vultosos lucros obtidos por empresas com a produção e venda de "pacotes educacionais" a serem assimilados e aplicados pelos professores, a realização de grandes consultorias, a implementação de políticas de avaliação externa em larga escala e outras ações empreendidas no crescente "mercado educacional", em um cenário de avanço da aliança neoliberal-neoconservadora, em diversos países, a partir da década de 1990.

De acordo com Diniz-Pereira (2011), modelos distintos disputam a hegemonia do campo da formação de educadores, seja ela inicial ou continuada. De um lado, estão os modelos que se fundamentam na racionalidade técnica e, de outro, aqueles que se filiam às racionalidades prática e crítica. Apoiado em escritos de autores que se valeram dos estudos de Habermas sobre o conhecimento e interesses humanos para descrever e analisar essas três racionalidades, Diniz-Pereira (2011, p. 19-28) apresenta características de modelos de formação de professores que se aproximam dessas racionalidades, aqui sumariadas:

- os modelos ligados à racionalidade técnica enfatizam o treinamento de habilidades comportamentais e são estruturados em função da transmissão de conteúdos ditos científicos, assumidos como suficientes para o trabalho de ensino. O professor é visto como um técnico que, de forma objetiva, deve pôr em prática os conhecimentos científicos e pedagógicos que estudou na formação;

- nos modelos pautados pela lógica da racionalidade prática, a prática não pode ser reduzida a uma soma de eventos previsíveis, controlados pela teoria. O professor é incentivado a refletir sobre os problemas da prática e a orientar suas ações em função de justificativas pedagógicas. O conhecimento não se reduz a um controle reprodutivista do manejo de alunos com vistas à obtenção de resultados esperados. São valorizados aspectos mais amplos do contexto escolar, como relações sociais e morais, distante ainda de uma intencionalidade transformadora;

- nos modelos construídos no bojo de uma racionalidade crítica, de forma geral, a práxis assume um papel fulcral no desvelamento da realidade. Trabalha-se em uma perspectiva problematizadora, na qual o professor constrói conhecimentos com os alunos, a partir de suas necessidades, tendo em vista a transformação da realidade e a promoção da justiça social.

Esses não são encontrados em estado puro, coexistem, e não se excluem mutuamente na concretude da formação e da prática docente, gerando até mesmo certos hibridismos. Contudo, princípios que se materializam naquilo que é priorizado na práxis pedagógica permitem reconhecê-los. 
Não obstante um conjunto de ações realizadas na contramão dos modelos convencionais de formação, as propostas que se apoiam na racionalidade técnica ocupam, hoje, a posição hegemônica. Em diferentes momentos político-econômicos, no decorrer da história, as visões de mundo que competem pela posição hegemônica na educação recebem maior ou menor visibilidade e apoio. O tempo presente, em que as decisões sobre a política educacional são pressionadas e condicionadas por critérios de crescimento econômico, em vários países da Europa e das Américas, favorece a tendência pela procura de soluções pragmatistas e individualistas para enfrentar problemas da educação e uma agenda de desregulamentação da formação docente.

Agências e organismos internacionais conservadores, como o Banco Mundial, bem como reformadores empresariais, têm impulsionado o desenvolvimento de políticas e práticas de educação e formação de professores como meio de "[...] interferir na formação do novo trabalhador e na quantidade de trabalhadores disponíveis, aumentando o controle sobre a escola e ocultando as raízes sociais das desigualdades acadêmicas". (FREITAS, 2014, p. 8). Apoiando-se em discursos que relacionam, mecanicamente, a melhoria da qualidade da educação e a formação de professores, reduzida, esta última, a um processo técnico de atualização dos docentes para o domínio de novos conhecimentos e tecnologias, agências e reformadores têm conseguido penetrar em diversas instituições formadoras e redes de educação, por meio de pesados financiamentos e/ou contratos de assessoria, principalmente nos países pobres e emergentes. (COCHRAN-SMITH et al., 2009).

Não raro, os grupos conservadores "sequestram" e subvertem, de acordo com seus interesses, bandeiras de luta tradicionalmente contra-hegemônicas, tais como: a gestão democrática e a formação de educadores para a justiça social. Fazem isso com o apoio da mídia de massa e a divulgação de pesquisas por eles produzidas, financiadas e avaliadas, gerando crenças e práticas que, por vezes, são acriticamente aceitas pela opinião pública, governos e até mesmo instituições educativas. Dessa maneira, alcançam seus objetivos de aumentar lucros e manter o controle da educação, desenvolvendo ações que reforçam a divisão social do trabalho, ampliam a distância entre teoria e prática e resultam em pouca ou nenhuma mudança efetiva em termos de qualidade social.

Imbernón (2010) assim se manifesta sobre o paradoxal discurso que associa linearmente ações de formação docente e melhoria da qualidade da educação, evidenciando as políticas e práticas que dominam o cenário da formação:

[...] há muita formação e pouca mudança. Talvez seja porque ainda predominam políticas e formadores que praticam com afinco e entusiasmo 
uma formação transmissora e uniforme, com predomínio de uma teoria descontextualizada, válida para todos sem diferenciação, distante dos problemas práticos e reais e fundamentada em um educador ideal que não existe. (IMBERNÓN, 2010, p. 39).

Com respeito à filosofia que sustenta essa perspectiva, acrescenta:

A base científica dessa forma de tratar a formação permanente do professorado foi historicamente o positivismo, uma racionalidade técnica que buscava com afinco na pesquisa educativa ações generalizadoras para levá-las aos diversos contextos educativos. (IMBERNÓN, 2013, p. 51).

Os escritos de Zeichner (2006), referindo-se ao contexto norte-americano de formação de educadores, e Vaillant (2003), com relação às políticas e práticas de formação de formadores em países da América Latina, reforçam a denúncia de que os modelos hegemônicos têm proporcionado pouca mudança, porque, em muitos casos, trabalham com uma perspectiva idealizada da prática docente e limitam-se a um campo retórico que não afeta os problemas reais dos professores e da escola.

Trabalhos relevantes ${ }^{2}$ que analisam a formação de educadores no Brasil, a partir dos anos 1990, chamam atenção para propostas, condições e problemas da formação de educadores, demonstrando a necessidade de que se desenvolvam estudos e práticas que caminhem na direção de superar as dificuldades ainda presentes e que ampliem os avanços até aqui conquistados.

Muito tem sido teorizado e esforços têm sido feitos, com o objetivo de incentivar e concretizar propostas contra-hegemônicas de formação docente que se opõem a modelos pré-estabelecidos, considerando a complexidade dos contextos concretos de prática e reforçando a autonomia dos professores, de modo a mobilizar saberes teóricos e práticos para construir novos conhecimentos, analisar criticamente a realidade e transformá-la. As produções de Giroux (1997), Freire (2001), Zeichner (2011) e Nóvoa (2009) são exemplos dos esforços realizados.

O valor e a atualidade do referencial de Paulo Freire são reconhecidos por Nóvoa (1998, p. 172): "Freire é o mais importante pedagogo de língua portu-

2 Ver as produções de Serbino et al. (1998); Gatti e Barreto (2009); André (2010); Gatti, Barreto e André (2011). 
guesa do século XX. A sua vida e a sua obra impõem-no como uma referência obrigatória, uma vez que transporta memórias e conceitos essenciais para o esforço científico de pensar a educação e a escola".

No espectro de teorias e práticas que se colocam em um mesmo campo crítico de preocupação com a formação de educadores, neste texto, será focalizada a proposta de Freire para a formação. Construída em seu trabalho como educador, acrescida de sua experiência como gestor público, ela agrega um referencial singular que articula as dimensões antropológica, ético-política, filosófica, epistemológica, metodológica e pedagógica e se mostra como um caminho possível para responder aos desafios da formação docente.

\section{A teoria e a prática de Paulo Freire: um paradigma contra-hegemônico para a formação de educadores}

A formação de educadores é um tema amplamente discutido por Paulo Freire, sob diferentes ângulos. A sua construção sobre esse tema derivou-se, ao mesmo tempo, de inspirações de sua prática, de diálogos que manteve com educadores em redor do mundo e de suas conviç̧ões sobre a relevância da formação no ato de educar.

Freire discute formação de educadores no conjunto de sua obra, em meio a tramas conceituais nas quais várias categorias do seu pensamento se entrelaçam: diálogo, relação teoria-prática, construção do conhecimento, democratização e outras, em uma moldura que mostra, com clareza, a politicidade da educação.

É possível afirmar que desde os seus primeiros escritos, Freire vai elaborando a sua concepção do saber fazer docente, quer dando ênfase aos fundamentos políticos, filosóficos e antropológicos de sua proposta, construindo, pois, o cenário para a compreensão da prática docente, quer aprofundando, em obras das décadas de 1980 e 1990, núcleos temáticos específicos relacionados ao ensinar-aprender e à formação dos educadores. E, especialmente, nas publicações: Medo e ousadia - o cotidiano do professor (1987), Professora sim, tia não: cartas a quem ousa ensinar (1993b), A educação na cidade (2001), Política e Educação (1993a), e, sobretudo, em Pedagogia da autonomia: saberes necessários à prática docente (1996), o autor sistematiza suas reflexões sobre o tema da docência e da formação de educadores.

Em sua proposta político-pedagógica no período que dirigiu a Secretaria Municipal de Educação de São Paulo (SME-SP), Paulo Freire deu grande ênfase à formação permanente dos educadores. Em suas palavras: 
[...] um dos programas prioritários em que estou profundamente empenhado é o de formação permanente dos educadores, por entender que os educadores necessitam de uma prática político-pedagógica séria e competente que responda à nova fisionomia da escola que se busca construir. (FREIRE, 2001, p. 80).

De acordo com A. M. Saul (1993), os princípios que nortearam o programa de formação permanente de educadores foram os seguintes:

a) o educador é o sujeito de sua prática, cumprindo a ele criá-la e recriá-la; b) a formação do educador deve instrumentalizá-lo para que ele crie e recrie a sua prática através da reflexão sobre o seu cotidiano; c) a formação do educador deve ser constante, sistematizada, porque a prática se faz e se refaz; d) a prática pedagógica requer a compreensão da própria gênese do conhecimento, ou seja, de como se dá o processo de conhecer; e) o programa de formação de educadores é condição para o processo de reorientação curricular; f) os eixos básicos do programa de formação de educadores precisam atender à fisionomia da escola que se quer, enquanto horizonte da nova proposta pedagógica, à necessidade de suprir elementos de formação básica aos educadores e à apropriação, pelos educadores, dos avanços científicos do conhecimento humano que possa contribuir para a qualidade da escola que se quer. (SAUL, 1993, p. 64).

Para Paulo Freire, a formação permanente pressupõe que o formador e o formando compreendam-se como seres inconclusos e que essa é uma condição humana que impele o homem a se enveredar, curiosamente, na busca pelo conhecimento de si e do mundo. Freire considera que essa é uma vocação ontológica e que, ao perceberem que o destino não está dado, os sujeitos possam, cada vez mais, ser capazes de (re)escrever suas histórias, contribuindo para a mudança da ordem social injusta que desumaniza e oprime. Nas palavras do autor:

A educação é permanente não porque certa linha ideológica ou certa posição política ou certo interesse econômico o exijam. A educação é permanente na razão, de um lado, da finitude do ser humano, de outro, da consciência que ele tem de sua finitude. Mais ainda, pelo fato de, ao longo da história, ter incorporado à sua natureza não apenas saber que vivia, mas saber que sabia e, assim, saber que podia saber mais. A educação e a formação permanente se fundam aí. (FREIRE, 1993a, p. 22-23). 
A formação permanente dos educadores, na gestão Paulo Freire ${ }^{3}$, abrangeu múltiplas modalidades, sendo a principal delas os "grupos de formação", nos quais se buscava garantir o princípio da ação-reflexão-ação. A proposta se diferenciava dos tradicionais "cursos de férias", "cursos de 30 horas", "treinamentos", "capacitações", "reciclagens" e outros que podem até receber avaliação positiva por parte dos educadores, no momento em que são realizados. No entanto, a repercussão desses cursos na prática cotidiana é, por vezes, considerada insatisfatória, pelos próprios educadores, por serem avaliados por eles como "muito teóricos" e desvinculados das necessidades do dia a dia.

Nos grupos, os educadores se reuniam, por adesão, em encontros periódicos e planejados, para discutir seu trabalho, expressar e aprofundar pressupostos teóricos decorrentes de necessidades advindas desse fazer, com a intenção de recriar a prática e a teoria e desenvolver a consciência crítica. Durante a gestão, os grupos foram se multiplicando e a adesão dos educadores se fez, de um lado, pelo ineditismo dessa proposta de formação que focalizava a prática concreta dos educadores, atendendo às suas necessidades e reivindicações e, de outro, às condições propiciadas pela Secretaria Municipal de Educação de São Paulo (SME-SP), oportunizando horários remunerados para estudo.

Os primeiros grupos de formação foram desenvolvidos com professores de Educação Infantil e alfabetizadores, congregando representantes de diferentes escolas. Na sequência, foram organizados grupos com coordenadores e diretores e algumas regiões desenvolveram também grupos de formação com pais. (SÃO PAULO, 1990).

A avaliação do trabalho com os grupos de formação logo mostrou a necessidade de que eles passassem a acontecer na escola.

Apostava-se na escola como um espaço coletivo de ensino-aprendizagem, na qual a formação se dirigia a todo o grupo de educadores, em oposição às formações em que os professores participam individualmente. Esperava-se que o educador pudesse experienciar, no grupo, o mesmo processo que era esperado que desenvolvesse junto aos educandos, nas escolas. Ou seja, uma prática de análise e de crítica da realidade, no transcurso de uma vivência da metodologia dialógica que permitisse a construção de conhecimentos com a compreensão de que o educador e o educando são sujeitos cognitivos, afetivos, sociais e históricos.

O documento "Cadernos de Formação - Grupos de Formação: uma (re) visão da educação do educador”, produzido pela SME-SP, apresenta características importantes que orientavam o trabalho nos grupos de formação:

3 O período 1989-1992 ficou conhecido como gestão Paulo Freire, dado que as propostas de política educacional, definidas no início da gestão, prosseguiram, durante todo o mandato da Prefeita, sob a direção do secretário Mario Sergio Cortella. 
O grupo de formação oportuniza ao educador momentos de troca, nos quais é valorizado o ser social, afetivo e cognitivo. É através dessa troca que o grupo irá se construindo, criando vínculos, permitindo que cada um resgate sua identidade pessoal e profissional, assumindo-se dentro e fora do grupo. Os conteúdos significativos emergidos em cada encontro, dado que nenhum grupo vive e cresce sem conteúdo, favorece a construção coletiva do conhecimento, a socialização do heterogêneo, a possibilidade de romper posturas cristalizadas. (SÃO PAULO, 1990, p. 10).

O desenvolvimento do trabalho nos grupos de formação estimulava a participação ativa dos educadores no seu processo educativo, em que a escuta e a voz dos participantes tinham destaque especial, pois era condição para um diálogo autêntico. Os grupos contavam com uma coordenação, que deveria se constituir em autoridade democrática, distante de posturas autoritárias e/ou espontaneístas. $\mathrm{O}$ coordenador utilizava diferentes estratégias para tornar possível o desenvolvimento da pauta de cada encontro, no qual ocorria o relato de práticas, o debate, a reflexão e o trabalho com aportes teóricos e o planejamento de próximos encontros. $\mathrm{O}$ coordenador do trabalho recebia assessoria e apoio de educadores que trabalhavam nos Núcleos de Ação Educativa ${ }^{4}$ (NAEs) e de equipes da Diretoria de Orientação Técnica (DOT).

Foi criada, nos grupos, uma "rotina não rotineira", na expressão de Paulo Freire, como forma necessária de organizar o tempo das ações previstas para cada encontro e marcar a constância das práticas ao longo do processo formativo. O trabalho contava com uma metodologia que incluía procedimentos e instrumentos, tais como observação, registro, reflexão, síntese e avaliação, cuja apreensão crítica, simultaneamente ao aprendizado da teoria e prática que permeavam as discussões, permitia aos educadores avançar na construção de sua autonomia profissional.

O documento "Cadernos de Formação - Grupos de Formação", anteriormente referido, amplia essa compreensão:

Os instrumentos metodológicos ajudam a compreender o momento vivido pelo grupo, articular os conteúdos que nele emergem e construir a disciplina intelectual e profissional. Através deles organizamos a ação pedagógica que nos permite não apenas planejar e coordenar ações mas também enfrentá-las para a mudança, pois o importante não é somente pensar, refletir, mas transformar. (SÃO PAULO, 1990, p. 13).

4 Na gestão Paulo Freire, os NAEs substituíram as Delegacias de Ensino (DE) e tinham como objetivo acompanhar e supervisionar o trabalho pedagógico das escolas em nível regional, valorizando a cultura local, sob a coordenação da DOT. 
Os grupos de formação tiveram como lócus principal a própria escola e o programa foi complementado com outras modalidades de formação: palestras, cursos, congressos e atividades culturais, em diferentes espaços. A integração da universidade a esse amplo programa de formação se deu de forma inovadora, alicerçada na compreensão de que a universidade e a rede pública seriam aprendentes e ensinantes nesse diálogo. (SAUL, 1993). Nesse sentido, superou propostas de formação docente em serviço que privilegiavam, sempre, um dos polos da produção de conhecimento, a universidade ou a escola, com preponderância da chamada teoria ou da prática.

A proposta de formação da gestão Paulo Freire influenciou um grande número de sistemas públicos de ensino e movimentos sociais alinhados com uma perspectiva progressista. Gatti e Barreto (2009) reconhecem o potencial indutivo das ações de formação desse período:

O Projeto Grupos de Formação desenvolvido pela Secretaria Municipal de São Paulo, entre 1989 e 1992, atingiu todas as escolas e adotou uma dinâmica de formação continuada que favoreceu o protagonismo do professor e da escola. O fator favorável à implementação do projeto foi a criação de um estatuto do magistério que previa 40 horas de trabalho semanais, sendo 20 em sala de aula e 20 dedicados a estudos, planejamentos, formação, remunerados. Estudos sobre processos de formação continuada com perfil semelhante, realizados em sistemas municipais, revelam seu alto potencial para induzir modificações significativas na educação local, mas seus efeitos positivos podem ser limitados em decorrência de situações de alternância de poder e mudanças programáticas de governo. (GATTI; BARRETO, 2009, p. 202).

Pesquisas recentes, no Brasil, têm demonstrado que esse paradigma de formação permanece vigente e em constante reinvenção.

\section{A presença de Paulo Freire nas pesquisas sobre formação de educadores na atualidade}

Paulo Freire foi docente do Programa de Educação: Currículo da PUC-SP, desde sua volta do exílio. Quando ele já não estava entre nós, em sua homenagem, a universidade criou, no segundo semestre de 1998, a Cátedra Paulo Freire, sob 
a direção do Programa de Pós-Graduação no qual Freire trabalhou. A Cátedra vem sendo compreendida como um espaço singular para o desenvolvimento de estudos e pesquisas sobre e a partir da obra de Paulo Freire, focalizando as suas repercussões teóricas e práticas na Educação e a sua potencialidade de fecundar novos pensamentos. Os estudos sobre Paulo Freire, nesse espaço, visam estudar criticamente o seu pensamento para compreendê-lo e reinventá-lo. O trabalho que vem se construindo na Cátedra tem o compromisso de não dicotomizar ensino e pesquisa, teoria e prática.

A pesquisa que se desenvolve na Cátedra, com o objetivo de identificar e analisar a influência do pensamento de Paulo Freire em espaços públicos de educação no Brasil, teve início em 2004, a partir da orientação de dissertações e teses de pós-graduandos que se interessavam pelo tema. Uma ação sistematizada a fim de tornar essa investigação ampliada e articulada, com a forte intenção de criar uma rede freireana de pesquisadores, ocorreu a partir do ano de 2010, quando o projeto que investigava a presença do pensamento de Paulo Freire na educação brasileira foi submetido ao Edital Universal 14/2010, e aprovado pelo Conselho Nacional de Desenvolvimento Científico e Tecnológico $(\mathrm{CNPq})^{5}$. Pretendeu-se adensar a massa crítica de estudos sobre a influência e reinvenção do pensamento de Paulo Freire, com a expectativa de que os resultados pudessem contribuir para a criação/recriação de políticas e práticas educativas, em contextos de educação, na perspectiva crítico-emancipatória. Quatro foram os eixos temáticos que balizaram essa investigação, extraídos da proposta político-pedagógica da gestão Paulo Freire: currículo, formação de educadores, gestão educacional e educação de jovens e adultos. Duas orientações metodológicas foram assumidas nessa pesquisa, que teve a sua segunda edição finalizada no ano de 2015. A primeira linha de investigação caracterizou-se pela análise de dissertações e teses, referenciadas no pensamento de Paulo Freire, registradas no Banco de Teses da Coordenação de Aperfeiçoamento de Pessoal de Nível Superior (CAPES), no período de 2013 a 2015. A segunda linha caracterizou-se pelo desenvolvimento de estudos empíricos, na abordagem qualitativa, nas modalidades estudo de caso e pesquisa-ação.

Na primeira linha de investigação, no eixo formação de educadores, foram selecionadas 34 produções (22 dissertações e 12 teses), a partir de critérios de mérito e viabilidade definidos para a pesquisa. Dos trabalhos pesquisados a partir do resumo, sumário, introdução e conclusões, foram identificados seis que se aproximavam com maior força do objeto de estudo da investigação, no eixo da formação: a busca da materialidade do pensamento de Paulo Freire, no tocante à formação permanente. Os principais pontos de aproximação foram:

5 Pesquisa coordenada pela professora Ana Maria Saul. 
Paulo Freire como referência central da pesquisa, presença de conceitos/categorias freireanas no âmbito da formação permanente, caracterização da pesquisa como um trabalho de investigação empírica e registro de recomendações para o campo de investigação e/ou para as políticas públicas.

No período de vigência da segunda edição da pesquisa, foram produzidos 25 estudos empíricos, sendo que nove ${ }^{6}$ deles referiam-se ao eixo formação de educadores. (SAUL, 2016). As pesquisas, nesse eixo, tomaram como objeto de investigação os temas: currículo, linguística, planejamento, ensino-aprendizagem, educação estética, perfis identitários de professores, representações sociais de educadores e práticas pedagógicas.

Os conceitos/categorias do pensamento freireano mais destacados nessas pesquisas foram: autonomia, participação, diálogo, relação teoria-prática e formação permanente. Esses conceitos tenderam, de maneira geral, a considerar e respeitar o pensamento do autor como uma referência a partir do qual são construídos entendimentos sobre as realidades tomadas como objeto de estudo.

Os estudos analisados demonstraram que as formações docentes que se apoiam na matriz crítico-emancipatória de educação têm contribuído para a construção da autonomia dos professores que delas participam. Participação compreendida como uma ação compartilhada, em que todos os sujeitos possam "ter voz" e intervir em diferentes níveis de poder, tendo o dever de não se omitir. Em "A Educação na Cidade", Freire expressa sua concepção dessa importante categoria:

Para nós, a participação não pode ser reduzida a uma pura colaboração que setores populacionais devessem e pudessem dar à administração pública. [...] Implica, por parte das classes populares, um “estar presente na História e não simplesmente nela estar representadas". Implica a participação política das classes populares através de suas representações, no nível das opções, das decisões e não só do fazer o já programado. [...] Participação popular para nós não é um slogan, mas a expressão e, ao mesmo tempo, o caminho para a realização democrática da cidade. (FREIRE, 2001, p. 75).

Registrou-se a importância de se assumir o diálogo como princípio fundante da formação. Nas pesquisas examinadas, identificou-se que os pesquisadores compreenderam que esse conceito não pode ser considerado simples troca de

6 Cavati (2013), Arnholdt (2014), Antoniuk (2015), Claudio (2015), Cunico (2015), Saul (2015), Leitão (2015), Santana (2015) e Lima (2015). 
ideias a serem consumidas pelos sujeitos que estão em interlocução e nem tampouco transformar-se em estratégia para depositar ideias de um sujeito no outro. Ao contrário, o diálogo, como diz Freire (1987), é uma exigência existencial, o encontro em que se solidariza o refletir e o agir de seus sujeitos endereçados ao mundo a ser transformado e humanizado.

Foi possível verificar, nos trabalhos analisados, a relevância da presença do diálogo para a formação de professores, seja ela inicial, continuada ou permanente, numa perspectiva da coletividade, do compartilhamento de saberes, do exercício da autonomia, do pensar a prática e de problematizá-la. A relação dialógica foi tratada, também, como propulsora da práxis pedagógica.

As dissertações e teses apontaram a necessidade de se trabalhar a partir dos saberes e das práticas dos docentes para que a formação resulte significativa. Salientaram a importância da leitura da realidade como ação indispensável no processo formativo dos educadores e, ainda, a exigência da realização de diálogos descodificadores do que fazer docente em um movimento de ação-reflexão-ação.

Nos trabalhos analisados, a formação permanente foi entendida como reflexão crítica sobre a prática que, problematizada, com a intenção de se conhecer e compreender suas múltiplas determinações e relações é também ponto de chegada da ação formativa transformadora. Freire (1996) ressalta que: “[...] na formação permanente dos professores, o momento fundamental é o da reflexão crítica sobre a prática. É pensando criticamente a prática de hoje ou de ontem que se pode melhorar a próxima prática". (FREIRE, 1996, p. 39).

Dentre os livros de Freire mais citados nos trabalhados analisados estão: Pedagogia da Autonomia, Pedagogia do Oprimido, Pedagogia da Esperança, Educação e Mudança, Educação como Prática da Liberdade, Medo e ousadia: o cotidiano do professor e Professora sim, tia não: cartas a quem ousa ensinar. Quanto às obras citadas, tiveram destaque os livros Pedagogia do Oprimido e Pedagogia da Autonomia. A obra clássica de Freire, Pedagogia do Oprimido segue sendo um livro seminal. Recentes informações situam a obra, também nos Estados Unidos, de acordo com dados do projeto The Open Syllabus Project ${ }^{7}$ 2015, entre os cem livros mais solicitados pelas universidades americanas, sendo o segundo mais indicado nas ementas da área da Educação.

Essas investigações destacam, também, algumas questões e dificuldades que ainda precisam ser equacionadas. Algumas delas apontam a necessidade de que haja maior apoio das equipes gestoras para práticas formativas que ousem desafiar os limites do que é estabelecido por programas autoritários de

7 Disponível em: <http://opensyllabusproject.org/a-syllabus-in-the-news/>. Acesso em: 16 fev. 2016. 
formação de educadores, pela cultura das instituições de formação ou mesmo pela política oficial. É consenso nos estudos a necessidade do fortalecimento de políticas democráticas de formação docente, que viabilizem ações contra-hegemônicas nas escolas e em outras instituições formadoras, impulsionando a luta dos educadores por condições mais dignas de trabalho e por uma educação de melhor qualidade para todos. Por fim, os trabalhos sublinham a urgência de que os professores se assumam como sujeitos de sua formação, mantendo uma postura crítica e curiosa diante dos desafios que se colocam no cotidiano escolar, sem, com isso, negar as condições desfavoráveis a que muitos deles estão submetidos, a exigência de que o trabalho de formação seja desenvolvido no coletivo e atribuir à formação um poder absoluto de transformação da educação.

\section{Últimas palavras}

A pesquisa "Paulo Freire na atualidade: legado e reinvenção", que analisou dissertações e teses e produziu estudos empíricos sobre a formação de professores, mostrou a contribuição do legado freireano para essa subárea de conhecimento, na atualidade, seja em programas de formação inicial e continuada, nos cursos de graduação e Pós-Graduação ou em espaços escolares e não escolares.

$\mathrm{Na}$ análise dos trabalhos foram encontradas, também, produções que demonstraram esforço em aproximar Paulo Freire de outros autores, buscando travar um diálogo entre eles. Todavia, essas análises sugerem a necessidade de um maior aprofundamento.

Os estudos demonstraram a possibilidade de que os educadores que participaram de formações alicerçadas na pedagogia de Freire construíssem novos conhecimentos e uma efetiva disposição para assumir práticas referenciadas no conceito de formação permanente.

A materialização e a reinvenção de aspectos da pedagogia freireana foram fortemente marcadas pela presença de proposições e práticas que visavam à construção de uma educação problematizadora. A materialização e recriação de conceitos do legado freireano foram evidenciadas pela concretude desses conceitos/categorias, em políticas e práticas. A reinvenção do pensamento freireano pode ser demonstrada pela possibilidade de criar/recriar novas compreensões e/ou ações, buscando manter, todavia, a precisão conceitual e a coerência com os fundamentos da pedagogia de Freire. Reinventar Paulo Freire exige uma releitura crítica dos pressupostos de sua obra, diante dos desafios que se colocam nos diferentes contextos concretos do tempo histórico. 
Em decorrência das análises realizadas pode-se afirmar a importância do paradigma da formação permanente para pesquisar e propor soluções para problemas contemporâneos do campo da formação docente, bem como o vigor e a atualidade desse paradigma enquanto proposta que supera a crítica sobre a prática, porque comprometida com a transformação social.

A formação permanente freireana como princípio para políticas, programas e práticas de formação de educadores pode se constituir em um compromisso ético a ser assumido por educadores críticos que desejam romper com o mito da neutralidade da educação e com a adaptação dos seres humanos a uma suposta vida em harmonia em uma sociedade marcada pela desigualdade. Significa pensar dentro da linguagem da possibilidade, em que o presente e o futuro podem ser criados e recriados, a partir de uma práxis social organizada coletivamente.

\section{REFERÊNCIAS}

ANDRÉ, M. E. D. de A. Formação de professores: a constituição de um campo de estudos. Educação, Porto Alegre, v. 33, p. 6-18, 2010.

ANTONIUK, M. Revisitando uma prática de formação à luz de referenciais freireanos: uma experiência em Moçambique-África. Dissertação (Mestrado em Educação: Formação de Formadores) - Pontifícia Universidade Católica de São Paulo, São Paulo, 2015.

ARNHOLDT, I. C. A. Formação permanente dos educadores no município de Guarulhos/ SP na perspectiva freireana. Dissertação (Mestrado em Educação: Currículo) - Pontifícia Universidade Católica de São Paulo, São Paulo, 2014.

CANDAU, V. M. Formação continuada de professores: tendências atuais. In: REALI, M. de M.; MIZUKAMI, M. da G. N. (Org.). Formação de professores: tendências atuais. São Carlos: EdUSFCar, 2007. p. 139-152.

CAVATTI, V. Práticas docentes de educação artística para o desenvolvimento da participação e diálogo: um estudo com os/as educandos/as do Proeja no Instituto Federal do Espírito Santo. Tese (Doutorado em Educação: Currículo) - Pontifícia Universidade Católica de São Paulo, São Paulo, 2013.

CELANI, M. A. A. A educação continuada do professor. SBPC Ciência e Cultura, São Paulo, v. 40, n. 2, p. 158-163, fev. 1998.

CLAUDIO, C. E. Política e práticas formativas em confronto na cidade de São Paulo a partir da gestão Paulo Freire (1989-1992): representação de professores sobre a escola. Tese (Doutorado em Educação: Currículo) - Pontifícia Universidade Católica de São Paulo, São Paulo, 2015. 
COCHRAN-SMITH, M.; FURLONG, J.; BRENNAN, M. (Ed.). Policy and Politics in Teacher Education: International Perspectives. London: Routledge Taylor \& Francis, 2009.

CUNICO, E. Pastoral da criança no Brasil: formação de líderes. Dissertação (Mestrado em Educação: Currículo) - Pontifícia Universidade Católica de São Paulo, São Paulo, 2015.

DINIZ-PEREIRA, J. E. A pesquisa dos educadores como estratégia para construção de modelos críticos de formação docente. In: ZEICHNER, K. M.; DINIZ-PEREIRA, J. E. (Org.). A pesquisa na formação e no trabalho docente. Belo Horizonte: Editora Autêntica, 2011.p. 11-38.

ESTRELA, M. T. A formação contínua entre a teoria e a prática. In: FERREIRA, N. S. C. (Org.). Formação continuada e gestão da educação. São Paulo: Cortez, 2006. p. 43-64.

FREIRE, P. Pedagogia do oprimido. Rio de Janeiro: Paz e Terra, 1987.

FREIRE, P. Política e educação. Indaiatuba: Villa das Letras Editora, 1993a.

FREIRE, P. Professora sim tia não: cartas a quem ousa ensinar. São Paulo: Paz e Terra, $1993 b$.

FREIRE, P. Pedagogia da autonomia: saberes necessários à prática educativa. São Paulo: Editora Paz e Terra, 1996.

FREIRE, P. A educação na cidade. São Paulo: Editora Cortez, 2001.

FREITAS, L. C. de. Os empresários e a política educacional: como o proclamado direito à educação de qualidade é negado na prática pelos reformadores empresariais. Germinal: Marxismo e Educação em Debate, Salvador, v. 6, n. 1, p. 48-59, jun. 2014. Disponível em: <http://www.portalseer.ufba.br/index.php/revistagerminal/article/view/12594/8857>. Acesso em: 20 ago. 2014.

GATTI, B. A.; BARRETO, E. S. de S. (Coord.). Professores do Brasil: impasses e desafios. Brasília: UNESCO, 2009.

GATTI, B. A.; BARRETO, E. S. de S.; ANDRÉ, M. E. D. de A. Políticas docentes no Brasil: um estado da arte. Brasília: UNESCO, 2011.

GIROUX, H. Os professores como intelectuais: rumo a uma pedagogia crítica da aprendizagem. Porto Alegre: Artmed, 1997.

IMBERNÓN, F. Formação continuada de professores. Porto Alegre: Artmed, 2010.

IMBERNÓN, F. Formação permanente do professorado: novas tendências. São Paulo: Cortez, 2013.

LEITÃO, E. S. S. A prática docente na perspectiva da humanização em Paulo Freire. Dissertação (Mestrado em Educação) - Universidade Federal de Pernambuco, Recife, 2015.

LIMA, T. S. de L. Formação de Professores/as: uma análise da Formação Continuada na perspectiva de Formação Permanente em Paulo Freire. Dissertação (Mestrado em Educação) - Universidade Federal da Paraíba, João Pessoa, 2015. 
MARCELO, C. Formação de professores: para uma mudança educativa. Porto: Porto Editora, 2013.

NÓVOA, A. (Coord.). Os professores e a sua formação. Lisboa: Publicações Dom Quixote, 1995.

NÓVOA, A. Notas sobre um regresso adiado. Educação, sociedade e culturas, Porto, n. 10, p. 155-174, 1998. Disponível em: <http://www.fpce.up.pt/ciie/revistaesc/ESC10/10-dialogos.pdf>. Acesso em: 10 jul. 2015.

NÓVOA, A. Professores: imagens do futuro presente. Lisboa: Educa, 2009.

SANTANA, E. de B. A autonomia docente no contexto da reforma curricular de cursos de licenciatura da UFPE. Dissertação (Mestrado em Educação) - Universidade Federal de Pernambuco, Recife, 2015.

SÃO PAULO (Município). Secretaria Municipal da Educação. Cadernos de Formação: grupos de formação, uma (re)visão da educação do educador. São Paulo, 1990.

SAUL, A. Para mudar a prática da formação continuada de educadores: uma pesquisa inspirada no referencial teórico - metodológico de Paulo Freire. Tese (Doutorado em Educação: Currículo) - Pontifícia Universidade Católica de São Paulo, São Paulo, 2015.

SAUL, A. M. Formação permanente de educadores na cidade de São Paulo. Revista da associação nacional de educação, São Paulo, v. 12, n. 19, p. 63-68, 1993.

SAUL, A. M. Relatório da pesquisa Paulo Freire na atualidade: legado e reinvenção - análise de sistemas de ensino a partir de 1990. São Paulo: PUC-SP, 2016. No prelo.

SERBINO, R. V.; RIBEIRO, R.; BARBOSA, R. L. L.; GEBRAN, R. A. (Org.). Formação de professores. São Paulo: Editora UNESP, 1998.

VAILLANT, D. Formação de Formadores: estado da prática. [S. 1.]: PREAL, 2003. Disponível em: <http://www.oei.es/docentes/articulos/formacion_formadores_estado_practica_vaillant_portugues.pdf $>$. Acesso em: 10 ago. 2014.

ZEICHNER, K. M. Different conceptions of teacher expertise and teacher education in the USA. Education Research and perspectives, Crawley, v. 33, n. 2, p. 60-79, 2006.

ZEICHNER, K. M. A pesquisa-ação e a formação docente voltada para a justiça social: um estudo de caso dos Estados Unidos. In: ZEICHNER, K. M.; DINIZ-PEREIRA, J. E. (Org.). A pesquisa na formação e no trabalho docente. Belo Horizonte: Editora Autêntica, 2011. p. 61-84.

Texto recebido em 22 de maio de 2016.

Texto aprovado em 22 de maio de 2016. 
